\title{
Synthesis and Application of Direct Dyes Derived From Terephthalic and Isophthalic Acids on Cotton Fabrics
}

\author{
J. E. Ishegbe, K. A. Bello and A. A. Kogo \\ Department of Textile Science and Technology, Ahmadu Bello University, Zaria
}

\begin{abstract}
The synthesis of direct dyes derived from terephthalic and isophthalic acid using $J$ and $H$-acids was undertaken with the view of replacing benzidine moiety in the production of direct dyes. The amide derivatives of isophthalic and terephthalic acids were used as the coupling components while aniline and its derivatives were used as the source of diazo components. The amide derivatives were characterized by Gas Chromatography/Mass Spectrometry and Infra-red analysis. The spectroscopic properties of the dyes in various solvents were also examined and most of the dyes showed bathochromic shifts when the solvent was changed to more polar solvents. The dyes also showed positive and negative halochromism with the addition of few drops of hydrochloric acid $(\mathrm{HCl})$. The synthesized dyes were applied to cotton fabrics and their performance properties evaluated. They have good exhaustion in the presence of electrolyte and have good wash fastness properties upon application of after-treating agents of values of 3-4, 4 and 4-5. They also had good fastness properties to light of values between 4-7. Their resistance to rubbing and perspiration had values between 3 and 4-5. The toxicity of the synthesized coupling components was studied using the Dietrich Lorke ( $L D_{50}$ ) method on Albino miceand they were found to be non-toxic.
\end{abstract}

Key words: Benzidine, direct dyes, exhaustion, electrolyte, cotton, fastness.

\section{Introduction}

Benzidine is an organic chemical belonging to the class of amines and used in making numerous dyestuffs. The azo dyes derived from benzidine are important because, unlike simpler classes of azo dyes, they become strongly fixed to cotton without a mordant [1].

It is well known that benzidine is both a mutagenic amine and a human carcinogen [2]. However, because benzidine is carcinogenic, its use for the production of dyes was forbidden. The problems associated with the synthesis of direct dyes from benzidine and urea dyes has resulted in the search for new dyes whose production and use would meet high environmental and safety requirements.

This work is focused on the possibilities of using terephthalic acid and isophthalic acid as "bridging groups" for the synthesis of symmetrical direct dyes. The spectral characteristics of the dyes and also a colorimetric evaluation of the dyes on woven cotton fabric were investigated.

\section{General information}

\section{Materials and methods}

All the chemicals used in the synthesis of the dyes and intermediates were of analytical gradeand were used without further purification. Melting points were determined by the open capillary method. The Visible absorption spectra were measured using Jenway UV-visible spectrophotometer; model: 6405. IR spectra were recorded using the FTIR infra- red spectrophotometer and the mass spectra were determined on a GC- MASS spectrometer.

Synthesis of coupling component using terephthalic acid and $\mathrm{J}$-acid as intermediate -N,N'-bis-(8 hydroxyl -6-sulphony-naphthalene-2-(3)-yl)-phthalamides of terephthalic acid (TJA).

Terephthalic acid $(8.3 \mathrm{~g}, 0.05 \mathrm{~mol})$ was heated with thionyl chloride $(11 \mathrm{ml})$ in chlorobenzene $(250 \mathrm{ml})$ in the presence of DMF $(1 \mathrm{ml})$ as catalyst [2]. The process was carried out at a temperature of $60-70^{\circ} \mathrm{C}$ for $6-$ 9hours. The obtained acidic chloride, without separation was used for the acylation of J-acid.

Acid chloride dissolved in chlorobenzene $(250 \mathrm{ml})$ was added to an aqueous solution of J-acid $(0.01 \mathrm{~mol}, 2.4 \mathrm{~g})$ at a temperature of $10^{\circ} \mathrm{C}$ and at such a rate as to obtain a $\mathrm{pH}$ of $6.8-7.2$ [2].The mixture was heated to $50^{\circ} \mathrm{C}$ and stirred at this temperature for 30 minutes. The solution was then cooled, its $\mathrm{pH}$ was adjusted to $7.5-7.75$ with $10 \%$ aqueous $\mathrm{NaOH}$ and the product was salted out,filtered, wash with brine $(\mathrm{pH}=7.7)$ and dried.

Synthesis of coupling component using terephthalic acid and $\mathrm{H}$-acid as intermediate - N,N'- bis-(8hydroxy-3, 6-disulphonynaphthalene-2-(3)-yl)-phthalamides of terephthalic acid (THA)

This was prepared in a similar manner as described above for TJA, except that $\mathrm{H}$-acid was used instead of Jacid. 
Synthesis of coupling component using isophthalic acid and $\mathrm{H}$-acid as intermediate - N,N' - bis-(8 hydroxyl -3,6 - disulphony - naphthalene - 2-(3)-yl)-phthalamides of isophthalic acid (ISH)

This was prepared in a similar manner as described above for THA, except that isophthalic acid was used instead of terephthalic acid.

Synthesis of coupling component using isophthalic acid and $\mathrm{J}$-acid as intermediate - N, N' - bis-(8 hydroxyl -6-sulphony-naphthalene-2-(3)-yl)-phthalamides of isophthalic acid (IJA).

This was prepared in a similar manner as described above for TJA, except that isophthalic acid was used instead of terephthalic acid.

\section{General Method Of Diazotisation}

Aniline, p-chloro aniline, p-nitroaniline and p-anisidine were diazotized in a conventional manner using direct and suspension methods [3].

Diazotisation of aniline and p- anisidine; The amines $(0.00365 \mathrm{~mol}, 0.4 \mathrm{~g}$ aniline $)$ and $(0.00365 \mathrm{~mol}, 0.5 \mathrm{~g} \mathrm{p}$ anisidine) were respectively dissolved in $1 \mathrm{ml}$ of $\mathrm{HCl}$ and cooled to $0-5^{\circ} \mathrm{C}$ in an ice bath equipped with a magnetic stirrer. Sodium nitrite $(0.7 \mathrm{~g}, 0.00673 \mathrm{moles})$ dissolve in $10 \mathrm{ml}$ of distilled water was added drop wisely over a period of 30 minutes while stirring for another 45 minutes. Urea $(0.5 \mathrm{~g})$ was then added to the mixture and stirring was continued for another 10 minutes to achieve complete diazotization.

\section{Diazotization of p-chloro aniline and p- nitro aniline}

The amine $(0.00365 \mathrm{~mol}, 0.5 \mathrm{~g})$ was dissolve in $1 \mathrm{ml}$ of hot concentrated $\mathrm{HCl}$ and cooled very rapidly to $0-5^{\circ} \mathrm{C}$ in an ice bath equipped with a magnetic stirrer by addition of ice to obtain a fine suspension of the aminehydrochloride. Sodium nitrite $(0.7 \mathrm{~g})$ dissolve in $10 \mathrm{ml}$ of distilled water was added drop wisely over a period of 30 minutes while stirring for another 45 minutes. Urea $(0.5 \mathrm{~g})$ was then added to the mixture and stirring was continued for another 10 minutes to achieve complete diazotization.

\section{Preparation of dyes $A_{1}, A_{2}, A_{3}$ and $A_{4}$}

Disazo dyes were prepared by coupling the diazotized amines (aniline, $\mathrm{p}$-anisidine, $\mathrm{p}$-chloroaniline and p-nitroaniline $(0.013 \mathrm{~mol})$ from above procedures with $(0.005 \mathrm{~mol}, 3.12 \mathrm{~g})$ of the coupling component $\left(\mathrm{N}, \mathrm{N}^{\prime}-\right.$ bis(8 - hydroxyl - 6 - sulphony - naphthalene-2-(3)-yl)-phthalamides of terephthalic acid)dissolved in $50 \mathrm{ml}$ of water at $\mathrm{pH}=12-12.5$ and $10-15^{\circ} \mathrm{C}$. The dye was salted out using $\mathrm{NaCl}(20 \%)$ filtered off and dried in air.

\section{Preparation of dyes $A_{5}, A_{6}, A_{7}$ and $A_{8}$}

The dyes were obtained by coupling the diazonium ions obtained from aniline, $\mathrm{p}$-anisidine, $\mathrm{p}$ chloroaniline and p-nitroaniline respectively, with $(0.005 \mathrm{~mol}, 3.63 \mathrm{~g})$ of the coupling component obtained using terephthalic acid and H-acid (N, N'-bis-(8-hydroxy-3,6-disulphony-naphthalene-2-(3)-yl)-phthalamides of terephthalic acid.

Preparation of dyes $\mathbf{B}_{1}, \mathbf{B}_{2}, \mathbf{B}_{3}$, and $\mathbf{B}_{4}$; The procedure is same as above, except that the coupling component used was obtained using J-acid and isophthalic acid- N,N'-bis-(8-hydroxy - 6-sulphony-naphthalene-2-(3)-yl)phthalamides of isophthalic acid (IJA)

Preparation of dyes $\mathbf{B}_{5}, \mathbf{B}_{6}, \mathbf{B}_{7}$ and $\mathbf{B}_{8}$; The procedure is same as above, except that the coupling component used was obtained using isophthalic acid and H-acid (N,N'-bis-(8-hydroxy-3,6-disulphony-naphthalene-2-(3)yl)-phthalamides of isophthalic acid) .

\section{Dyeing and fastness properties measurement}

The dye bath was prepared using a liquor ratio of 50:1; the volume of dye required was $2 \mathrm{ml}$ to give $2 \%$ depth of shade on weight of fabric measured in a beaker.1g of cotton fabric was wetted in water for 1 minute and excess water squeezed out. The wetted fabric was then introduced into the beaker/dye bath containing electrolyte $(0.7 \mathrm{~g} \mathrm{NaCl})$, on a thermostated steam bath with the dyeing liquor temperature at $40^{\circ} \mathrm{C}$ and raised to the boil after a period of 30 minutes while constantly agitating the sample. The dyeing was carried out at this temperature for 1 hour. After dyeing was completed, the fabric was removed,thoroughly rinsed in cold running tap water and dried in air at room temperature. The optical density of the dye bath liquor was measured before and after dyeing for the calculation of percentage exhaustion.

Wash fastness using current I.S.O 3 washing tests [4], light fastness, fastness to rubbing and perspiration were determined by the standard procedure [5]. The results are summarized in Table 5 and Table 6 respectively.

Effect of varying the concentration of electrolyte, effect of varying dyeing time on exhaustion,effect of temperature on dyeing and effect of varying percentage shade on dyeing and exhaustion were also studied.

Aftertreatment of the dyed samples and wash fastness test 
An aftertreatment was carried out on the dyed samples using $8 \%$ formaldehyde, liquor ratio of $50: 1$, at $60^{\circ} \mathrm{C}$ for 60 minutes for each sample. The samples were removed, rinsed in water and dried. The wash fastness test as stated above was carried out on the after treated samples and the results are shown in Table 5

\section{Acute toxicity test}

The acute toxicity test was carried out in two steps;

1. In the initial investigation,the range of doses producing the toxic effects was established.

2. Based on these results, further specific doses were administered to calculate an $\mathrm{LD}_{50}[12]$.

This is achieved by giving widely differing doses to the animals. e.g. $10,100,1000 \mathrm{mg} / \mathrm{kg}$ body weight. The result shows whether the substance is very toxic, toxic, lesstoxic, or only slightly toxic.

Albino mice were used for this test. The mice were weighed and the doses were given based on the mice's weight.

Three (3) animals each was injected for each dose $(10,100,1000 \mathrm{mg} / \mathrm{kg}$ body weight) making a total of nine (9) mice for the initial investigation. Their body reactions were observed immediately and at intervals for 72 hours [13].

Further higher doses of $600,1000,1600,2900 \mathrm{mg} / \mathrm{kg}$ body weight were prepared and injected into another set of four new animals and its effects was examined and observed at interval for another 72 hours. The number of death that occurred was recorded and the $\mathrm{LD}_{50}$ was calculated from the minimum toxic dose and maximum tolerated dose [12]. The results are shown in Table 3.

\section{Results and Discussion.}

Synthesis of the dyes and intermediates.

Four coupling components were synthesized in the present study. The first two were obtained by heating terephthalic acid in chlorobenzenefor 6-9 hours at a $\mathrm{pH}$ of $6.8-7.2$ in the presence of dimethylformamide as a catalyst. Further reactions were made by reacting the acidic chlorides of terephthalic acids obtained with J-acid and $\mathrm{H}$-acid respectively. The molar mass of N,N' - bis-( 8 - hydroxyl -6 - sulphony - naphthalene - 2-(3)-yl)-phthalamides of terephthalic acid (TJA)was 624 and has a melting point of $265^{\circ} \mathrm{C}$ and the colour obtained was brownish with a yield of $81 \%$,while N,N'-bis-(8-hydroxy - 3,6 - disulphony naphthalene-2-(3)-yl)-phthalamidesof terephthalic acid (THA)has a molar mass of 726 and a melting point of $270^{\circ} \mathrm{C}$. The colour obtained was black and has a yield of $79 \%$.
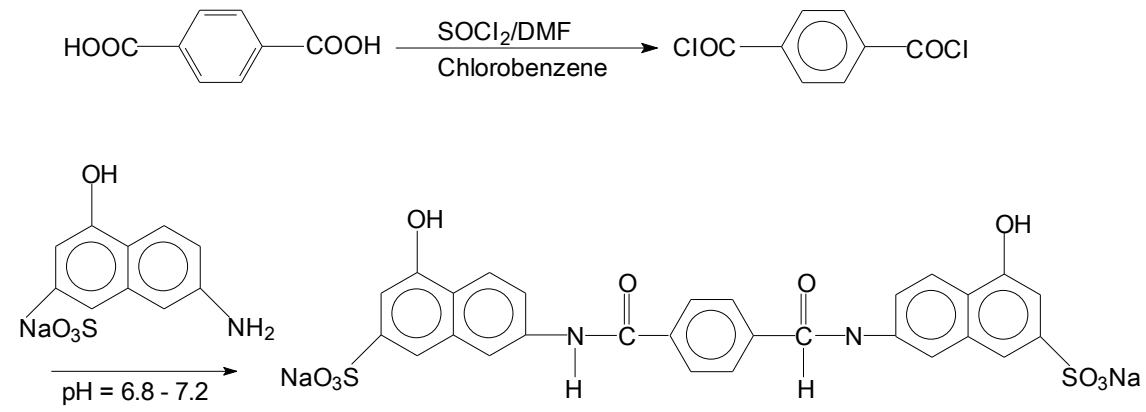

Scheme 1: Synthesis of coupling component using terephthalic acid and J-acid as intermediate - N, N' - bis - (8 - hydroxyl - 6 - sulphony - naphthalene - 2 - (3) -yl) - phthalamides of terephthalic acid (TJA)

The other two coupling components were obtained by heating isophthalic acid in chlorobenzene as above and the acidic chlorides of isophthalic acids were reacted further with J-acid and $\mathrm{H}$-acid respectively.

N,N' - bis-(8 - hydroxyl -6-sulphony - naphthalene-2-(3)-yl)-phthalamides of isophthalic acid (IHA)has a molar mass of 624 and a melting point of $266^{\circ} \mathrm{C}$. The colour was brownish and it has a yield of $78 \%$. While N,N' - bis-(8-hydroxy-3,6 - disulphony - naphthalene-2-(3)-yl)-phthalamides of isophthalic acid (ISH) has a molar mass of 726 and a melting point of $260^{\circ} \mathrm{C}$. The colour obtained was cream and it has a yield of $80 \%$. These were synthesized based on the literature methods [2]. The physical characteristics are shown in Table1. The coupling components were studied and analysed using GC-Mass spectrometry. 


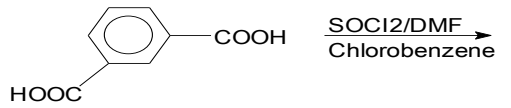

CI OC
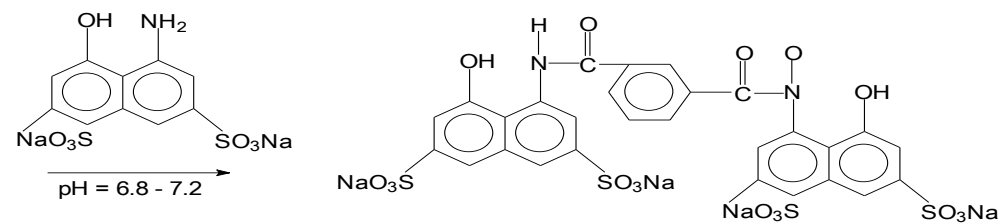

Scheme2: Synthesis of coupling component using isophthalic acid and $\mathrm{H}$-acid as intermediate N, N' - bis - (8 hydroxyl - 3, 6- disulphony - naphthalene - 2 - (3)-yl) -phthalamides of isophthalic acid (ISH).

The dyes synthesized were obtained by diazotising four primary aromatic amines namely; aniline, $p$-anisidine, p-chloroaniline and p-nitroaniline using direct and suspension methods of diazotisation. The diazo component was each coupled to the four coupling components obtained to get sixteen different dyes. The yields of the dyes were relatively high and the dyes had sharp melting point which may be due to absence of impurity. The colours of crystals obtained were bright ranging from different shades of orange, purple, brown, green, navy blue and red. The colours of the dyed materials were of bright and brilliant shades as well.

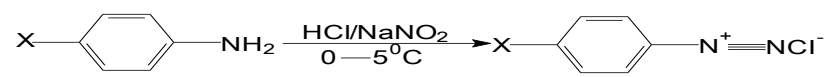

(a) Diasotization of primary amine.
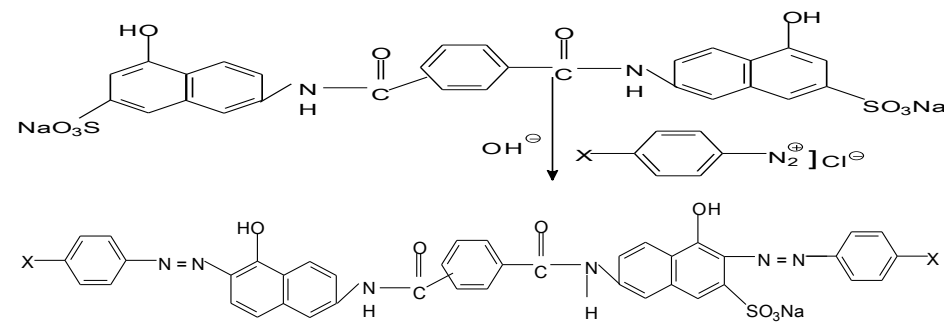

$\mathrm{X}=\mathrm{H}, \mathrm{CH}_{3}, \mathrm{Cl}, \mathrm{NO}_{2}$

Scheme 3: Reaction of the diazotized amine with the coupling component

Table 1; Physical Characteristics Of The Dyes.

Dye No. Molar Mass $\left(\mathrm{Gmol}^{-1}\right)$ Melting Point $\left({ }^{0} \mathrm{c}\right) \quad \%$ Yield Colour Of Crystal Colour Of Dyed Sample

\begin{tabular}{llllll}
\hline \hline$A_{1}$ & 834 & $116-117$ & 81 & Orange & Yellow \\
$A_{2}$ & 847 & 199 & 72 & Purple & Brown \\
$A_{3}$ & 903 & 226 & 64 & Deep Orange & Brown \\
$A_{4}$ & 878 & $242-245$ & 68 & Brown & Dark brown \\
$A_{5}$ & 834 & 208 & 70 & Deep orange & Orange \\
$A_{6}$ & 847 & 205 & 69 & Purple & Brown \\
$A_{7}$ & 903 & 206 & 80 & Orange & Brown \\
$A_{8}$ & 878 & 209 & 74 & Brown & Dark brown \\
$B_{1}$ & 1040 & 238 & 72 & Brown & Yellow \\
$B_{2}$ & 1053 & $241-246$ & 83 & Light purple & Pink \\
$B_{3}$ & 1109 & 262 & 78 & Dark green & Light green \\
$\mathrm{B}_{4}$ & 1084 & 245 & 81 & Dark purple & Army green \\
$\mathrm{B}_{5}$ & 1040 & 183 & 75 & Orange & Yellow \\
$\mathrm{B}_{6}$ & 1053 & $190-191$ & 68 & Darkgreen & Light green \\
$\mathrm{B}_{7}$ & 1109 & 200 & 72 & Purple & Light purple \\
$\mathrm{B}_{8}$ & 1084 & 155 & 73 & Navy blue & Army green \\
ISH & 726 & 260 & 80 & Cream & - \\
THA & 726 & 270 & 79 & Black & - \\
TJA & 624 & 265 & 81 & Brownish & - \\
IJA & 624 & 266 & 78 & brownish & - \\
& & & & & \\
\hline
\end{tabular}

ISH $=$ N, N' - bis - (8-hydroxyl - 3, 6 - disulphony - naphthalene - 2 - (3) -yl) - phthalamides of isophthalic acid

THA = N, N'-bis-(8-hydroxy - 3, 6- disulphony - naphthalene - 2 - (3) - yl) - phthalamides of terephthalic acid TJA = N, N'-bis-(8-hydroxy - 6 - sulphony - naphthalene -2 - (3) - yl) - phthalamides of terephthalic acid IJA = N, N' - bis - (8- hydroxyl - 6 - sulphony - naphthalene-2 - (3) -yl) - phthalamides of isophthalic acid. 


\section{The infra-red spectra of some of the dyes.}

The infra-red spectra of the dyes showed similar or closely related absorption band due to presence of similar groupings or bonds present in the dye structures.Dye $\mathrm{A}_{1}, \mathrm{~A}_{2}$, and $\mathrm{A}_{3}$ obtained from, N, N'-bis-( 8-hydroxy - 6 - sulphony - naphthalene - 2 - (3) - yl) - phthalamides of terephthalic acid showabsorption peaks due to double bonds $-\mathrm{C}=\mathrm{C}$ - in aromatic rings between the range $1631-1642 \mathrm{~cm}^{-1}$. The presence of acarbonyl group $\mathrm{C}=\mathrm{O}$ gave rise to a stretching vibrations in these dyes between $1642-1840 \mathrm{~cm}^{-1}$. They also gave N-H bending vibrations at region of $1631-1642 \mathrm{~cm}^{-1}$. The peak due to hydrogen bond stretching shows a peak due to vibrations of hydrogen and other atoms [6].

At a region of between $3392-3425 \mathrm{~cm}^{-1}$ hydrogen bonding broadens the peak and shifts them to lower wavelength. They also show absorption peaks due to $\mathrm{C}=\mathrm{N}$ stretching at a region of $1631-1642 \mathrm{~cm}^{-1}$ and peaks due to $\mathrm{C}-\mathrm{SO}_{3} \mathrm{H}$ at $1250-1300 \mathrm{~cm}^{-1}$.

Dyes $A_{5}$ and $A_{7}$ obtained from, N, N'-bis-( 8-hydroxy - 3, 6 - disulphony - naphthalene - 2 - (3) - yl) phthalamides of terephthalic acid shows absorption peaks due to double bonds $-\mathrm{C}=\mathrm{C}$ - in aromatic rings between the range $1640 \mathrm{~cm}^{-1}$. The presence of a carbonyl group $\mathrm{C}=\mathrm{O}$ gave rise to a stretching vibrations at $1646 \mathrm{~cm}^{-1}$. They also gave N-H bending vibrations at region of $1641-1642 \mathrm{~cm}^{-1}$. The peak due to hydrogen bond stretching shows a peak due to vibrations of hydrogen at a region of between $3442 \mathrm{~cm}^{-1}$. Hydrogen bonding broadens the peak and shifts them to lower wavelength. They also show absorption peaks due to $\mathrm{C}=\mathrm{N}$ stretching at a region of $1641-1642 \mathrm{~cm}^{-1}$ and peaks due to $\mathrm{C}-\mathrm{SO}_{3} \mathrm{H}$ at $1300-1310 \mathrm{~cm}^{-1}$.

Dyes $\mathrm{B}_{3}$ and $\mathrm{B}_{7}$ shows absorption peaks due to double bonds $-\mathrm{C}=\mathrm{C}$ - in aromatic rings between the range $1575-1630 \mathrm{~cm}^{-1}$. The presence ofacarbonyl group $\mathrm{C}=\mathrm{O}$ gave rise to a stretching vibrations at $1651 \mathrm{~cm}^{-}$ ${ }^{1}$.They also gave N-H bending vibrations at region of $1646-1651 \mathrm{~cm}^{-1}$. The peak due to hydrogen bond stretching shows a peak due to vibrations of hydrogen at a region of between $3394-3422 \mathrm{~cm}^{-1}$. They also showed absorption peaks due to $\mathrm{C}=\mathrm{N}$ stretching at a region of $1646-1651 \mathrm{~cm}^{-1}$ and peaks due to $\mathrm{C}-\mathrm{SO}_{3} \mathrm{H}$ at 1275 $1350 \mathrm{~cm}^{-1}$.

Generally all the dyes have absorption peaks due to $-\mathrm{N}=\mathrm{N}$ - stretching at between $1575-1631 \mathrm{~cm}^{-1}$ which is prominent in all dyes spectra. These regions are in conformity with the characteristics of IR absorption peaks [7].

\begin{tabular}{cllllllll}
\hline $\begin{array}{l}\text { Table 2; THE INFRA-RED SPECTRA OF THE DYES } \\
\text { Functionalgroup }\end{array}$ & $-\mathrm{N}=\mathrm{N}-$ & $-\mathrm{C}=\mathrm{C}$ & $\mathrm{C}=\mathrm{O}$ & $\mathrm{N}-\mathrm{H}$ & $\mathrm{C}=\mathrm{N}$ & $\mathrm{C}-\mathrm{H}$ & $\mathrm{O}-\mathrm{H}$ & $\mathrm{CSO}_{3} \mathrm{H}$ \\
\hline Type of vibration & stretching & bending & stretching & bending & stretching & stretching & stretching & \\
\hline $\mathrm{A}_{3}$ & 1575 & 1642 & 1642 & 1642 & 1642 & 3000 & 3425 & 1260 \\
$\mathrm{~B}_{3}$ & 1630 & 1646 & 1651 & 1646 & 1646 & 2850 & 3422 & 1350 \\
$\mathrm{~A}_{7}$ & 1580 & 1642 & 1646 & 1642 & 1642 & 2940 & 3442 & 1300 \\
$\mathrm{~A}_{1}$ & 1550 & 1642 & 1558 & 1642 & 1642 & 3192 & 3392 & 1300 \\
$\mathrm{~A}_{2}$ & 1631 & 1631 & 1634 & 1631 & 1631 & 2085 & 3420 & 1250 \\
$\mathrm{~B}_{7}$ & 1575 & 1651 & 1651 & 1651 & 1651 & 2087 & 3394 & 1275 \\
$\mathrm{~A}_{5}$ & 1630 & 1641 & & 1641 & 1641 & & & 131 \\
\hline
\end{tabular}

\begin{tabular}{|c|c|c|c|c|c|c|c|c|}
\hline \multicolumn{9}{|c|}{ THA-stage 1} \\
\hline STOCK & $10 \mathrm{mg} / \mathrm{ml}$ & & $100 \mathrm{mg} / \mathrm{ml}$ & & & $1000 \mathrm{mg} / \mathrm{ml}$ & & \\
\hline no on mouse & wt of mouse(g) & Vol. of injection $(\mathrm{ml})$ & no on mouse & wt of mouse $(\mathrm{g})$ & Vol. of injection & no on mouse & wt of mouse & Vol. of injection \\
\hline 1 & 21 & 0.21 & 4 & 20 & 0.2 & 7 & 27 & 0.27 \\
\hline 2 & 21 & 0.21 & 5 & 21 & 0.21 & $8^{*}$ & 20 & 0.2 \\
\hline 3 & 30 & 0.3 & 6 & 24 & 0.24 & 9 & 20 & 0.2 \\
\hline
\end{tabular}

\begin{tabular}{llllll} 
Stage 2 & \multicolumn{5}{l}{} \\
\hline STOCK & $600 \mathrm{mg} / \mathrm{ml}$ & $1000 \mathrm{mg} / \mathrm{ml}$ & $1600 \mathrm{mg} / \mathrm{ml}$ & $2900 \mathrm{mg} / \mathrm{ml}$ \\
\hline & No on mouse & 1 & 2 & 3 & $4^{*}$ \\
Weight of mouse $(\mathrm{g})$ & 31 & 36 & 29 & 31 \\
Volume of injection(ml) & 0.31 & 0.36 & 0.29 & 0.31
\end{tabular}

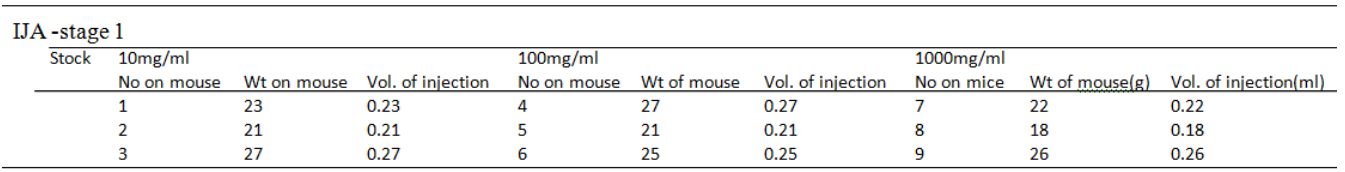

\begin{tabular}{cllll} 
Stage 2 & \multicolumn{3}{l}{} \\
\hline Stock & $1200 \mathrm{mg} / \mathrm{ml}$ & $1600 \mathrm{mg} / \mathrm{ml}$ & $2900 \mathrm{mg} / \mathrm{ml}$ & $5000 \mathrm{mg} / \mathrm{ml}$ \\
\hline No on mice & 1 & 2 & $3^{*}$ & $4^{*}$ \\
Weight of mice & 23 & 25 & 26 & 28 \\
Volume of injection & 0.23 & 0.25 & 0.26 & 0.28 \\
\hline
\end{tabular}

$\mathrm{LD}_{50}=[\text { Maximum tolerated dose } \mathrm{x} \text { minimum toxic dose }]^{1 / 2}$

$=[1600 \times 2900]^{1 / 2}=2154$ 
The synthesized coupling components were used for the acute toxicity test. The test was carried out in two stages. In the initial investigation, different doses of $10 \mathrm{mg} / \mathrm{ml}, 100 \mathrm{mg} / \mathrm{ml}$ and $1000 \mathrm{mg} / \mathrm{ml}$ were prepared and given to the animals (albino mice) based on their respective body weight (which was obtained using a weighing balance) as shown in Table 3 . After injecting the substance into the 9 albino micethey were observed for 72 hours for change in body reaction based on the effect of the injected substance. At the end of 48hours,only mice number 8 of $20 \mathrm{~g}$ which was injected with $0.2 \mathrm{ml}$ of $1000 \mathrm{mg} / \mathrm{ml}$ in stage 1 died.

In stage 2, Further higher doses $(600 \mathrm{mg} / \mathrm{ml}, 1000 \mathrm{mg} / \mathrm{ml}, 1600 \mathrm{mg} / \mathrm{ml}$ and $2900 \mathrm{mg} / \mathrm{ml})$ were given to 4 mice to establish a toxic effect. At the end of 72 hours, mice number 4 having $31 \mathrm{~g}$ body weight which was injected with $0.31 \mathrm{ml}$ of $2900 \mathrm{mg} / \mathrm{ml}$ concentration died. The maximum tolerated dose is $1600 \mathrm{mg} / \mathrm{ml}$ and the minimum toxic dose is $2900 \mathrm{mg} / \mathrm{ml}$.

Similarly, using IJA coupling component,the same procedure was followed in stage 1as above and none of the 9 mice died after 24 and 48 hours.

In stage 2, further higher doses $(1200 \mathrm{mg} / \mathrm{ml}, 1600 \mathrm{mg} / \mathrm{ml}, 2900 \mathrm{mg} / \mathrm{ml}$ and $5000 \mathrm{mg} / \mathrm{ml})$ were given to the 4 mice. At the end of 72 hours,mice number 3 which was injected with $2900 \mathrm{mg} / \mathrm{ml}$ and mice number 4 which was injected with $5000 \mathrm{mg} / \mathrm{ml}$ died. Therefore, the maximum tolerated dose is also $1600 \mathrm{mg} / \mathrm{ml}$ and the minimum toxic dose is $2900 \mathrm{mg} / \mathrm{ml}$. Therefore, an $\mathrm{LD}_{50}$ was calculated and obtained as 2154 to establish a range of toxicity using the above formula. Therefore the coupling components (THA and IJA) used was non-toxic based on the $\mathrm{LD}_{50}$ obtained from the test. This may be due to the low $\mathrm{LD}_{50}$ value of 2154 , as values above 5000 have toxic effect [13].

\section{Spectroscopic properties of the dyes:}

The maximum absorption wavelengths in distilled water, dimethylformamide, ethanol, ethanol + hydrochloric acid are shown in Table 4.

TABLE 4:Spectroscopic properties of the dyes

\begin{tabular}{|c|c|c|c|c|c|c|}
\hline \multicolumn{3}{|c|}{ Dye $\mathrm{No} \varepsilon_{\max } \times 10^{4}$ in water $\mathrm{Lmol}^{-1} \mathrm{~cm}^{-1} \lambda_{\max }$ in water $(\mathrm{nm})$} & \multicolumn{4}{|c|}{$\lambda_{\max }$ in DMF(nm) $\lambda_{\max }$ in ethanol(a) $\lambda_{\max }$ in ethanol +a drop of $\mathrm{HCl}(\mathrm{b})$ Change in $\lambda_{\max }(\mathrm{b}-\mathrm{a})$} \\
\hline$A_{1}$ & & & 503 & 510 & 315 & \\
\hline $\mathrm{A}_{2}$ & 4.93 & 505 & 510 & 505 & 510 & +5 \\
\hline $\mathrm{A}_{3}$ & 6.16 & 480 & 505 & 505 & 510 & +5 \\
\hline $\mathrm{A}_{4}$ & 4.41 & 490 & 505 & 505 & 505 & 0 \\
\hline $\mathrm{A}_{5}$ & 8.33 & 485 & 505 & 510 & 505 & -5 \\
\hline $\mathrm{A}_{6}$ & 7.89 & 495 & 535 & 505 & 510 & +5 \\
\hline $\mathrm{A}_{7}$ & 8.09 & 505 & 510 & 510 & 505 & -5 \\
\hline$A_{8}$ & 5.79 & 500 & 505 & 505 & 505 & 0 \\
\hline $\mathrm{B}_{1}$ & 9.79 & 510 & 505 & 510 & 510 & 0 \\
\hline $\mathrm{B}_{2}$ & 5.25 & 480 & 510 & 510 & 510 & 0 \\
\hline $\mathrm{B}_{3}$ & 7.69 & 480 & 505 & 510 & 515 & +5 \\
\hline $\mathrm{B}_{4}$ & 5.34 & 505 & 520 & 505 & 505 & 0 \\
\hline $\mathrm{B}_{5}$ & 8.79 & 505 & 525 & 505 & 510 & +5 \\
\hline $\mathrm{B}_{6}$ & 7.23 & 520 & 510 & 510 & 515 & +5 \\
\hline $\mathrm{B}_{7}$ & 8.58 & 505 & 505 & 505 & 508 & +3 \\
\hline $\mathrm{B}_{8}$ & 7.05 & 510 & 505 & 505 & 505 & 0 \\
\hline
\end{tabular}

From the results in Table 4, dye $A_{1}$ which was obtained from aniline using N, N'-bis-(8-hydroxy - 6 sulphony - naphthalene - 2 - (3) - yl) - of terephthalic acid (TJA) absorbed at 510nm in distilled water. Dye $\mathrm{A}_{2}$ obtained using $\mathrm{p}$ - anisidine and TJA as coupling component absorbed at $505 \mathrm{~nm}$. Similarly, dye $\mathrm{A}_{3}$ and $\mathrm{A}_{4}$ obtained from p- chloroaniline and p- nitroaniline using TJA as coupling component absorbed at $480 \mathrm{~nm}$ and $490 \mathrm{~nm}$ respectively. Thus dye $A_{1}$ is more bathochromic than dyes $A_{2}, A_{3}$ and $A_{4}$ as it absorbed at a longer wavelength.

Dyes $\mathrm{A}_{5}, \mathrm{~A}_{6}, \mathrm{~A}_{7}$ and $\mathrm{A}_{8}$ were obtained using N, N' -bis-(8-hydroxy - 6 - sulphony - naphthalene - 2 (3) - yl) - phthalamides of isophthalic acid (IJA). $\mathrm{A}_{5}$ absorbed at $485 \mathrm{~nm}$ in distilled water while dyes $\mathrm{A}_{6}, \mathrm{~A}_{7}$ and $\mathrm{A}_{8}$ absorbed at $495 \mathrm{~nm}, 505 \mathrm{~nm}$ and $500 \mathrm{~nm}$ respectively in distilled water. Thus, dyes that absorbed at a lower wavelength indicate that they require higher energy for excitation.

Dye $\mathrm{B}_{1}$ obtained from aniline using N, N'-bis-(8-hydroxy - 3,6 - disulphony - naphthalene - 2 - (3) yl) - phthalamides of terephthalic acid(THA) absorbed at $510 \mathrm{~nm}$ in distilled water. Dyes $\mathrm{B}_{2}$ and $\mathrm{B}_{3}$ obtained from THA both absorbed at a wavelength of $480 \mathrm{~nm}$ in distilled water while dye $\mathrm{B}_{4}$ absorbed at $505 \mathrm{~nm}$. Thus dye $\mathrm{B}_{1}$ is more bathochromic than $\mathrm{B}_{2}, \mathrm{~B}_{3}$ and $\mathrm{B}_{4}$ by a wavelength of $30 \mathrm{~nm}$ and $5 \mathrm{~nm}$ respectively.

Similarly, dyes $\mathrm{B}_{5}$ obtained from aniline using isophthalic acid and H-acid to obtain N, N'-bis - (8-hydroxy - 3, 6 - disulphony - naphthalene - 2 - (3) - yl) - phthalamides of isophthalic acid(IHA) absorbed at $505 \mathrm{~nm}$ in distilled water. $\mathrm{B}_{6}, \mathrm{~B}_{7}$ and $\mathrm{B}_{8}$ obtained using same coupling component $\mathrm{IHA}$ absorbed at $520 \mathrm{~nm}, 505 \mathrm{~nm}$ and $510 \mathrm{~nm}$ respectively. Thus dye $\mathrm{B}_{6}$ is more bathochromic than $\mathrm{B}_{5}, \mathrm{~B}_{7}$ and $\mathrm{B}_{8}$, while dyes $\mathrm{B}_{5}$ and $\mathrm{B}_{7}$ are more hypsochromic than dyes $\mathrm{B}_{6}$ and $\mathrm{B}_{8}$.

Spectrophotometric measurements therefore showed that the spectra of the disazo dyes possesses visible absorption peaks whose intensity changes with the polarity of the solvent. This is probably due to the aggregation of the dyes [15]. A strongly polar solvent such as water considerably affected the spectra/absorption maxima of the dyes. The dyes derived from J-acid, derivatives of terephthalic acid $\left(\mathrm{A}_{1}-\mathrm{A}_{4}\right)$, exhibited bathochromic shift in relation to bands of dyes derived from isophthalic acid $\left(\mathrm{A}_{5}-\mathrm{A}_{8}\right)$. While in the case of dyes 
derived from $\mathrm{H}$-acid,an opposite effect was observed, i.e the absorption bands of dyes derived from terephthalic acid $\left(\mathrm{B}_{1}-\mathrm{B}_{4}\right)$ shifted hypsochromically in relation to dyes derived from isophthalic acid $\left(\mathrm{B}_{5^{-}} \mathrm{B}_{8}\right)$. This confirms the existence of conjugation between two parts of dye.

\section{Solvatochromic effects}

With increasing polarity of the solvent, the absorption maximum is shifted to longer wavelengths [13]. The interaction of the solvent with the dye molecule is greater in polar solvent [8]. Most of the shifts in maximum absorption wavelength observed were bathochromic for majority of the dyes where measurements were done in solvent of higher polarity. For most of the dyes, the maximum absorption wavelengths values shifted to longer wavelengths when the solvent is changed from ethanol to dimethylformamide(DMF). Although some of the dyes had negative solvatochromism, i.e a hypsochromic shift to lower wavelength in the visible absorption spectrum when the solvent was changed from ethanol to dimethylformamide. Some of the dyes showed no change in wavelengths from ethanol to DMF, for example, dye $A_{3}, A_{4}, A_{7}, A_{8}, B_{1}, B_{6}, B_{7}$ and $B_{8}$. This is a clear indication that, the visible band is due to $\pi----\rightarrow \pi^{*}$ transition since a positive solvatochromism occurred in some of the dyes and $\mathrm{n}----\rightarrow \pi^{*}$ transition since a negative solvatochromism also occurred in some of the dyes [10].

\section{Halochromism (Effect of acid on visible absorption band)}

Eight of the synthesized dyes exhibit positive halochromism (for examples dyes $A_{1}, A_{2}, A_{3}, A_{6}, B_{3}, B_{5}$, $B_{6)}$,) in acidic ethanol solution, indicating a bathochromic shift of $+5 \mathrm{~nm}$ in the dyes above. Also dye $\mathrm{B}_{7}$ in a neutral solution of ethanol absorbed at $505 \mathrm{~nm}$ but maximally absorbed at $508 \mathrm{~nm}$ in acidic ethanol solution, indicating a bathochromic shift of $+3 \mathrm{~nm}$.

However,some of the dyes showed a negative halochromism. For example, dyes $\mathrm{A}_{5}$ and $\mathrm{A}_{7}$ absorbed in neutral ethanolic solution both at $510 \mathrm{~nm}$ but absorbed maximally both at $505 \mathrm{~nm}$ in acidic solution of ethanol, indicating a hypsochromic shift of $-5 \mathrm{~nm}$. The dyes that exhibited positive and negative halochromism can be used as indicators in acid-base titration.

\section{Fastness properties of the dyes.}

The wash fastness results before after- treatment of the dyed fabric as shown in Table 5 were in the range of very poor to poor, rating of between 1-3 on the grey scale, except for dye $\mathrm{B}_{1}$ which had moderate fastness of $3-4$. This poor wash fastness is as a result of the presence of two or more sulphonic acid groups present in high molecular weight direct dyes which makes them water-soluble in the dye bath and on the fibre. This accounts for the relative ease with which the dye is removed from the fibre on washing in water [12]. The poor wash fastness is also attributed to the characteristics of direct dyes on cellulose when not aftertreated.

Fastness to washing upon the after-treatment process: As a result of the poor wash fastness properties obtained, the original samples were subjected to an after treatment process using $8 \%$ formaldehyde. The results obtained are shown in Table 5.

Table 5: Fastness rating to washing

\begin{tabular}{|c|c|c|c|c|}
\hline DYE NC & $\begin{array}{l}\text { CHANGE INCOLOUR STAINING } \\
\text { Rating before aftertreatment }\end{array}$ & ON COTTON & $\begin{array}{l}\text { CHANGE IN COLOUR } \\
\text { Rating upor }\end{array}$ & $\begin{array}{l}\text { STAINING ON COTTON } \\
\text { naftertreatment }\end{array}$ \\
\hline$A_{1}$ & 3 & 4-5 & $4-5$ & 5 \\
\hline$A_{2}$ & 2 & 3 & $3-4$ & 4 \\
\hline$A_{3}$ & 3 & 3 & 4 & 4 \\
\hline$A_{4}$ & 3 & $3-4$ & $4-5$ & 5 \\
\hline$A_{5}$ & 2 & 3-4 & $3-4$ & $4-5$ \\
\hline$A_{6}$ & $2-3$ & 3 & 4 & $4-5$ \\
\hline$A_{7}$ & 3 & 3 & 4 & $4-5$ \\
\hline$A_{8}$ & 2 & 3-4 & $4-5$ & 5 \\
\hline $\mathrm{B}_{1}$ & $3-4$ & $4-5$ & $4-5$ & 5 \\
\hline $\mathrm{B}_{2}$ & 2 & $4-5$ & $4-5$ & 5 \\
\hline $\mathrm{B}_{3}$ & 2 & 4-5 & 4 & 5 \\
\hline $\mathrm{B}_{4}$ & 2 & 4-5 & 4 & 4 \\
\hline $\mathrm{B}_{5}$ & $3-4$ & $4-5$ & $4-5$ & 5 \\
\hline$B_{6}$ & 2 & $4-5$ & 4 & $4-5$ \\
\hline $\mathrm{B}_{7}$ & $1-2$ & $4-5$ & 4 & 5 \\
\hline $\mathrm{B}_{8}$ & 3 & $4-5$ & 4-5 & $4-5$ \\
\hline
\end{tabular}

The results were greatly improved as all the dyes had good to moderate fastness to washing of between 3- 4, 4 and 4-5 as compared on the grey scale while staining on the adjacent fabric are from $4-5$ indicating that they are rarely stained. This after-treatment worked on the principle of increasing the size of the dye molecule or decreasing the solubility in water by forming a methylene linkage between two of the dye molecule. Either of these effects restricts the ability of the dye to diffuse out of the fibre during washing [3]. 
Table 6: Fastness to rubbing and light fastness ratings of the dyed samples.

\begin{tabular}{|c|c|c|c|c|c|}
\hline DYENO & DRY & WET & DRY & WET & LGHTRATING \\
\hline & \multicolumn{2}{|c|}{ CHANGE IN COLOUR } & \multicolumn{2}{|c|}{ STAINING ON COTTON } & \\
\hline$A_{1}$ & $4-5$ & 5 & 4 & 5 & 6 \\
\hline$A_{2}$ & 5 & $4-5$ & 5 & 4 & 5 \\
\hline$A_{3}$ & 5 & 4 & 5 & 4 & 6 \\
\hline $\mathrm{A}_{4}$ & 5 & 4 & 5 & 4 & 5 \\
\hline$A_{5}$ & 5 & $4-5$ & 5 & $4-5$ & 5 \\
\hline$A_{6}$ & $4-5$ & 4-5 & 4-5 & 4 & 5 \\
\hline$A_{7}$ & 5 & $4-5$ & 5 & $4-5$ & 4 \\
\hline$A_{B}$ & 5 & 4 & 5 & 4 & 6 \\
\hline$B_{1}$ & 5 & $4-5$ & 5 & $4-5$ & 7 \\
\hline $\mathrm{B}_{2}$ & 5 & $4-5$ & 5 & $4-5$ & 5 \\
\hline $\mathrm{B}_{3}$ & $4-5$ & 4-5 & $4-5$ & $4-5$ & 5 \\
\hline $\mathrm{B}_{4}$ & 5 & $4-5$ & 5 & $4-5$ & 7 \\
\hline$B_{5}$ & $4-5$ & 4-5 & 4-5 & $4-5$ & 4 \\
\hline$B_{6}$ & 5 & 4 & 5 & $4-5$ & 4 \\
\hline $\mathrm{B}_{7}$ & 5 & 4 & 4-5 & 4 & 5 \\
\hline $\mathrm{B}_{8}$ & $4-5$ & $4-5$ & $4-5$ & $4-5$ & 7 \\
\hline
\end{tabular}

Table 7: Fastness to perspiration

\begin{tabular}{lllll}
\hline & \multicolumn{3}{c}{ ALKALINE } & \multicolumn{1}{c}{ ACID } \\
DYE NO & CHANGE IN SHADE & STAINING & CHANGE IN SHADE & STAINING \\
\hline $\mathrm{A}_{1}$ & 3 & 4 & 4 & 4 \\
$\mathrm{~A}_{2}$ & 3 & 3 & 3 & 4 \\
$\mathrm{~A}_{3}$ & 4 & 4 & 3 & 3 \\
$\mathrm{~A}_{4}$ & 3 & 3 & 3 & 3 \\
$\mathrm{~A}_{5}$ & 3 & 3 & 3 & 3 \\
$\mathrm{~A}_{6}$ & 3 & 2 & $3-4$ & 4 \\
$\mathrm{~A}_{7}$ & 4 & 3 & 4 & 4 \\
$\mathrm{~A}_{8}$ & 3 & 3 & 4 & 5 \\
$\mathrm{~B}_{1}$ & 4 & 4 & 4 & 5 \\
$\mathrm{~B}_{2}$ & 4 & 5 & 4 & 4 \\
$\mathrm{~B}_{3}$ & 3 & 4 & 4 & 4 \\
$\mathrm{~B}_{4}$ & 4 & 4 & 4 & 4 \\
$\mathrm{~B}_{5}$ & 4 & 4 & 3 & 4 \\
$\mathrm{~B}_{6}$ & 4 & 4 & 4 & 5 \\
$\mathrm{~B}_{7}$ & 3 & 4 & 3 & \\
$\mathrm{~B}_{8}$ & 4 & 3 & 5 & \\
\hline
\end{tabular}

The fastness to rubbing was done using a crockmeter and the results show that they have very good fastness to rubbing using wet and dry fabric. The results in Table 7 shows that the dyed samples in alkaline solution of histidine had good fastness properties to perspiration based on ratings between 3 and 4, with little and moderate staining on the adjacent fabric while the dyed samples in acidic solution had better resistance to perspiration based on rating of 3,4 and 5 mostly for all the dyes. They also had good to moderate fastness to light.

\section{Conclusion}

The synthesis of direct dyes from terephthalic and isophthalic acid using J-acid and $\mathrm{H}$-acid was undertaken. The type of bridging group used affects $\lambda_{\max }$ only to a slight extent, which indicate the transition of conjugation by the diamidesystem. The chosen method of acid chloride synthesis in an organic solvent (chlorobenzene) allows one to prepare products in a simple way, preventing partial decomposition. The selected method for the synthesis of disazo dyes is simple and makes it possible to prepare dyes in high yield.

Generally, the exhaustion of the dyes were very good on cotton fabric with poor wash fastness properties.Though, improvement was made upon after-treating the dyed samples with formaldehyde. They had good to moderate fastness to light, rubbing and perspiration. These dyes had bright and some deep shades on cotton due to high exhaustion and greater planarity of the dyes.

Based on the performance properties obtained, one can state that the obtained dyescan replace urea dyes and dyes derived from benzidine with similar structures.

Their practical properties such as light fastness, etc. especially those of the derivatives of J-acid are higher than those of the H-acid derivatives except for fastness to perspiration where the latter is better. The type of bridging group used in the dye synthesis plays an important part, with the best effect being obtained with the derivatives of isophthalic acid. They are observed to be relatively non-toxicand therefore can be used to dye apparel.

\section{References}

[1]. Schwenecke, H. Mayer, D. (2005). Benzidine and benzidine derivatives, Ullmann's Encyclopedia of industrial chemistry, Weinheim: Wiley -VCH.Pp101-104

[2]. K. Wojciechowski and Szadowski J, (2003), Direct dyes derived from terephthalic and isophthalic acid. Dyes and Pigment 56, 99109

[3]. Perkins S.W, (1996), Textile colouration and finishing, Carolina Academic Press, Durham, North Carolina. Pp 102, 112-129, 122126

[4]. $\quad 4$.Nunn, D. M. (1979). The dyeing of synthetic polymer and acetate fibres. (Bradford Dyers Co. Publication Trust).Pp $243-256$.

[5]. H. R. Maradiya and V. S. Pattel (2002), Thiopene based monoazo disperse dyes for polyester fabric, Journal of the Serbian Society, 67(1) $17-25$ 
[6]. Koji N and Philippa H.S (1997). Infra-red absorption spectroscopy. $2^{\text {nd }}$ Edition London ,Pp 22-33

[7]. Khopkar, S. M. (2008). Basic concept of analytical chemistry, New age international publisher, India. Pp 112-120,183, 290-292, $450-457$

[8]. Reichardt C. and Welton, T. (2010).Solvents and solvents effect in organic chemistry. $2^{\text {nd }}$ Rev and Enl. Ed. Weinham; VCH. Pp 360

[9]. Watson E. R. (1918). Colour in relation to chemical constitution.Longmans green, London. Pp 89

[10]. Venkataraman K. (1970). The chemistry of synthetic dyes. Vol III. Academic Press. London. Pp 373-383

[11]. Venkataraman K. (1972). The chemistry of synthetic dyes. Vol VI. Academic Press. London. Pp 287-291

[12]. Zbinden G and Flury-Rovers M. (1981), Significance of the LD ${ }_{50}$ test for the toxicological evaluation of chemical substances. Arch Toxicity 47;77-99.

[13]. Bass, R. Gunzel, P. Henschler D. Konig J. Lorke D, Neubert D, Schuppan D, Zbinden G. (1982). LD 50 Versus acute toxicity, Critical assessment ofthe methodology currently in use. Arch toxicol 51:183-186

[14]. Nkeonye, P.O. (1993), Introductory Textiles, Ahmadu Bello University Press, Zaria.Pp 53, 108-109

[15]. March, J. (1992). Advance organic chemistry. ( $8^{\text {th }}$ edition). J. Wiley and sons. New York. Pp 23-48

[16]. Bird C. L and Boston W. S, (1975). The theory of coloration of textile dyers company publication, England. Pp 265-267

[17]. Colour Index (1999), Vol. 2, 4. $3^{\text {rd }}$ Ed. Bradford SDC.

[18]. Doree, C. (1947). The methods of cellulose chem. Chapman \& Hall, London. Pp 12.

[19]. Ferreira LFN, Reixo F and Garcia AR J, (1992). Chemical Society Faraday Trans;pp88(1):15 and 1993;89(12):

[20]. Hsieh B .R, Desilets D, Kazmaier P. M. (1990). Dyes and pigment:114:165.

[21]. Iyun, O. A, (2008), Synthesis of dyes derived from 2- amino heterocycles and their dyeing performance on polymeric materials. M.Sc Thesis, AbubakarTafawaBalewa University Bauchi. pp 88, 91-94

[22]. Joseph, P. D. (1985). Oxidative activation of benzidine and its derivatives by peroxidases. 64: 171-178.

[23]. J. Shore Ed. (1990). Colorants and Auxillaries. Vol 1, Bradford SDC. Pp $9-24$

[24]. K. J. Sakoma (2011). Synthesis of Azo dyes derived from pyridine as coupling components and their application on nylon and polyester fabrics. M.Sc thesis, Ahmadu Bello University, Zaria.

[25]. Kirk Othmer, (1965), Dyes and their intermediates. ( $2^{\text {nd }}$ Edition) In; Encyclopedia of Chemical Technology. Vol 7,Wiley Inter science Publishers. N.Y, pp. 34-65

[26]. Lillie, R. D. (1997).Conn's Biological Stains. $9^{\text {th }}$ Edition Publication. Williams and Wilkins, Baltimore, Pp 493-502

[27]. Rys P and Zollinger H. (1972). Fundamentals of the chemistry and application of dyes. Wiley Interscience, London, Pp 84

[28]. S.D.C (1991). Standard methods for the determination of the colour fastness of textiles and leather. $5^{\text {th }}$ Edition. Bradford

[29]. Szadowski J, Niewiadomski Z, Wojciechowski K.(2001), Dyes \& Pigments; 50: 87.

[30]. Trotman E.R. (1984), Dyeing and chemical technology of textile fibres. $6^{\text {th }}$ Edition, Wiley Interscience Publication, London. Pp $24-$ 40 